\title{
Case report: an unusual cause for hypocalcemia
}

\begin{abstract}
Severe hypocalcemia in the clinical setting is most commonly seen in the post thyroidectomy patient because of transient/permanent hypoparathyroidism because of intraoperative injury. ${ }^{1}$

Sometimes it is seen as part of an autoimmune polyendocrine syndrome. ${ }^{2}$ Rarely is it seen as a part of PTH receptor resistance. Here we report a case with characteristic phenotypical abnormalities and multiple electrolyte deficiencies and anemia.
\end{abstract}

Volume 5 Issue 2 - 2017

George Koshy T,Amruth Raj

Department of Medicine, Syrian Church Medical College, India

Correspondence: George Koshy T,Associate Profesor, Endocrine Unit, Department of Medicine, Malankara Orthodox Syrian Church Medical College, Kolencherry, Ernakulam 68231।, Kerala, India,Tel+919633446430, Email dsgkoshy@gmail.com

Received: March 26, 2017| Published: July 21, 2017

\section{Introduction}

The commonest cause for hypocalcemia in clinical practice is iatrogenic hypoparathyroidism seen in the typical setting of the post thyroidectomy patient. ${ }^{1}$ Occasionally it is seen in the setting of autoimmune primary hypoparathyroidism along with other polyendocrine deficiencies. ${ }^{2}$ Rarely is it seen as a part of PTH-receptor resistance. Here we report a case of severe hypocalcemia with high normal PTH along with severe anemia and multiple electrolyte abnormalities

\section{Case summary}

1. In 2015 we had from the department of Medicine seen one unusual case of hypocalcemia-the lady had presented with severe proximal muscle weakness and was practically bedbound when she came to us, she was found to have severely low serum calcium with high normal serum PTH with low potassium.

2. A 50year old unmarried lady, ms RJ, presented with generalised fatigue, malaise, decreased appetite and cramps and posturing of upper and lower limbs, she was able to do her own activities till about 2 weeks back, now bed bound.

3. She was a known case of hypothyroidism on levothyroxine replacement.

4. On examination she was short stature, oriented and conscious but drowsy. She had short and stubby fingers and toes.

5. Her vital signs and systemic examination within normal limits.

6. Patient was found to havemarked hypocalcemia, hypomagnesemia and hypokalemia-all three electrolyte deficiencies were corrected over the course of hospital stay with IV replacement.

7. Her serum PTH was high normal.

8. She was found to have marked anemia-etiological work up showed features of megaloblastic anemia with high MCV and macrocytes in the peripheral smear and Vitamin B12 deficiencythis was treated with parenteral B12 replacement and 2 pints of packed cell transfusion.

9. This was fitting into the phenotype of Albert's Hereditary Osteodystrophy.

10. High normal PTH also brought on a possibility of pseudohypoparathyroidism.
11. She had markedly low potasium and magnesium possibly secondary to renal tubular loss.

12. She had UTI with E coli which responded clinically to IV cefotaxime followed by oral cefixime.

13. As part of the work up for anaemia some pertinent investigations were done: MCV:120.1(NR-82-92fl)

14. Peripheral smear: Pancytopenia-macrocytic anemia with polychromasia, nucleated RBCs, mild leucopenia and thrombocytopenia.

15. Serum iron: $93 \mathrm{ug} \%(37-170)$.

16. Serum ferritin $375 \mathrm{ng} / \mathrm{ml}(11.1-264)$.

17. Serum folic acid $>20 \mathrm{ng} / \mathrm{ml}(3.1-20)$.

18. TIBC-136.

19. \%Transferrin saturation- $80.15(20-40 \%)$.

20. Se Vit B12 asay:196 pg/ml(N 239-931).

21. Reticulocyte count of $2 \%$.

22. Hemoglobin on admission was only $5.7 \mathrm{gm} / \mathrm{dl}-2$ pints of packed cells were transfused and vitamin B12 was administered as a daily injection.

23. She was found to have marked hyoocalcemia along with hypokalema -for these treatment was started on appropriate replacements.

24. Patient was found to havemarked hypocalcemia, hypomagnesemia and hypokalemia-all three electrolyte deficiencies were corrected over the course of hospital stay with IV replacement.

25. Her serum PTH was high normal.

26. She was found to have marked anemia-etiological work up showed features of megaloblastic anemia with high MCV and macrocytes in the peripheral smear and Vitamin B12 deficiencythis was treated with parenteral B12 replacement and 2 pints of packed cell transfusion.

27. Work up for anemia (Tables $1 \& 2$ ).

28. Hence we made a diagnosis of: Hypothyroidism with Hypocalcemia possibly secondary to Pseudohypoparathyroidism with associated Albright's Hereditary Osteodystrophy and 
hypokalemia, hypomagnesemia possibly secondary to renal tubular loss and megaloblastic anemia.

29. To complete our work up we did a serum cortisol(14.9ug\%) and $\mathrm{FSH}(15.09 \mathrm{mIU} / \mathrm{ml})($ normal range: follicular phase-3$8 \mathrm{mIU} / \mathrm{ml}$, mid cycle peak $2.5-16.69 \mathrm{mIU} / \mathrm{ml}$, luteal phase 1.38 $5.47 \mathrm{mIU} / \mathrm{ml}$ ) both of which were normal ruling out an associated hypocortisolemia and hypogonadotropic hypogonadism.

30. She was discharged on high dose oral calcium and rocaltrol (I,25 dihydroxy vitmain D), methylcobalamine injections and milk of magnesia to correct the mentioned deficiencies.

31. She came for follow up till March 2015 but never after that.

Table I Work up for anemia

\begin{tabular}{|c|c|c|c|c|}
\hline Haematology & Normal range & $4 / 2 / 2015$ & $8 / 2 / 2015$ & $9 / 2 / 2015$ \\
\hline $\mathrm{Hb}(\mathrm{gm} \%)$ & $12-|5 \mathrm{gm} / \mathrm{d}|$ & 5.7 & 8.1 & 12.7(post transfusion 2pints of packed cells) \\
\hline TC & $4000-1 \mathrm{I}, 000 / \mathrm{mm}^{3}$ & 4500 & & \\
\hline DC Neutrophils & $40-60 \%$ & 70 & & \\
\hline Lymphocytes & $20-40 \%$ & 22 & & \\
\hline Monocytes & $2-10 \%$ & 4 & & \\
\hline Eosinophils & $1-6 \%$ & 2 & & \\
\hline \multicolumn{5}{|l|}{ Basophils } \\
\hline Bandforms & & 2 & & \\
\hline Reticulocytes & & 2 & & \\
\hline ESR & & 15 & & \\
\hline
\end{tabular}

MCV, I20.I (NR-82-92 fl);

Peripheral smear, pancytopenia-macrocytic anemia with polychromasia, nucleated RBCs, mild leucopenia and thrombocytopenia;

Serum iron, 93ug \%( 37-170);

Serum ferritin375ng/ml(II.I-264)

Serum folic acid $>20 \mathrm{ng} / \mathrm{ml}(3 . \mathrm{I}-20)$

TIBC-I36

\%Transferrin saturation-80.15(20-40\%)

Se Vit BI 2 asay: 196pg/ml(N 239-931)

Table 2 Serial values of electrolytes during hospital admission

\begin{tabular}{|c|c|c|c|c|c|c|c|c|}
\hline Biochemistry & $4 / 2 / 2015$ & $5 / 2 / 2015$ & $5 / 2 / 2015$ & $6 / 2 / 2015$ & $7 / 2 / 2015$ & $8 / 2 / 2015$ & $9 / 2 / 2015$ & $10 / 2 / 2015$ \\
\hline Sodium & 144 & & & & & & & \\
\hline \multicolumn{9}{|l|}{$130145 \mathrm{mmol} / \mathrm{l}$} \\
\hline Potassium & 1.8 & 2 & 2.5 & 3.9 & 5.3 & 4 & & \\
\hline \multicolumn{9}{|l|}{$3.5-5 \mathrm{mmol} / \mathrm{l}$} \\
\hline \multicolumn{9}{|l|}{ Creatinine } \\
\hline \multicolumn{9}{|l|}{$0.6-1.4 \mathrm{mg} / \mathrm{dl}$} \\
\hline $\begin{array}{l}\text { Serum calcium } \\
(8.5-10.5 \mathrm{mg} \%)\end{array}$ & 3.4 & & & 5.1 & 7 & 8.1 & & 7.5 \\
\hline $\begin{array}{l}\text { Serum magnesium } \\
\text { (1.8-2.8mg \%) }\end{array}$ & I.I & & & 1 & 1.2 & 2.7 & & 1.8 \\
\hline $\begin{array}{l}\text { Phosphorous } \\
\text { (2.5-4.5mg \%) }\end{array}$ & & 1.7 & & 1.9 & & 3.8 & & 3.9 \\
\hline $\begin{array}{l}\text { TSH } \\
(0.46-4.68 \mathrm{ulU} / \mathrm{ml})\end{array}$ & & 0.19 & & & & & & \\
\hline $\begin{array}{l}\text { Free T4 } \\
(0.8-2.19 \text { ug \%) }\end{array}$ & & 1.22 & & & & & & \\
\hline $\begin{array}{l}\text { PTH } \\
(15-75 p g / m l)\end{array}$ & & 66.1 & & & & & & \\
\hline $\begin{array}{l}\text { Cortisol } \\
\text { (4.47-22.lug \%) }\end{array}$ & & & 14.9 & & & & & \\
\hline
\end{tabular}




\section{Discussion}

Pseudohypoparathyroidism (PHP) is a heterogeneous group of disorders characterized by hypocalcemia, hyperphosphatemia, increased serum concentration of parathyroid hormone (PTH), and insensitivity to the biologic activity of PTH. Several variants of PHP have been identified. The molecular defects in the gene (GNAS1) encoding the alpha subunit of the stimulatory $G$ protein (Gsa) contribute to at least 3 different forms of the disease: PHP type 1a, PHP type $1 \mathrm{~b}$, and pseudopseudohypoparathyroidism (pseudo-PHP). ${ }^{3}$ PHP type 1a is the best understood form of the disease.

a. In 1942, Fuller Albright first introduced the term pseudohypoparathyroidism to describe patients who presented with PTH-resistant hypocalcemia and hyperphosphatemia along with an unusual constellation of developmental and skeletal defects, collectively termed Albright hereditary osteodystrophy (AHO).

b. The constellation of findings includes short stature with obesity, ${ }^{4}$ round face and marked brachymetacarpals and brachymetatarsals.

c. In addition, administration of PTH failed to produce the expected phosphaturia or to stimulate renal production of cyclic adenosine monophosphate (cAMP).

d. In 1998, a nationwide epidemiologic survey of PHP was conducted in Japan based on hospital visits in 1997; the period prevalence was 3.4 cases per 1 million people. ${ }^{5}$ No information is available regarding the prevalence of PHP in the rest of the world.

e. PHP occurs approximately twice as frequently in females as in males. Patients' ages range from infancy to senescence.

f. A study by Sanchez et al found that an imprinting defect in GNAS may lead to growth plate defects in patients with PHP type $1 \mathrm{~b}$, including brachydactyly and Madelung deformity. This suggests that GNAS signaling has a more extensive role in chondrocyte maturation than was previously believed. ${ }^{6}$

g. Patients with PHP type 1a may have disturbances in taste, smell, vision, and hearing, and they may be hyporesponsive to the biologic effects of other peptide hormones that use the alpha subunit of the Gsa protein to enhance cAMP production. The hormones under this class include thyrotropin, antidiuretic hormone, the gonadotropins, glucagon, adrenocorticotropin, and growth hormone-releasing hormone.

h. Primary hypothyroidism occurs in most patients with PHP type 1a. ${ }^{7,8}$

i. Reproductive dysfunction commonly occurs in persons with PHP type 1a. Women may have delayed puberty, oligomenorrhea, and infertility.

j. Features of hypogonadism may be less obvious in men. Testes may show evidence of maturation arrest or may fail to descend normally. Fertility appears to be decreased in men with PHP type 1a.
Mentation is impaired in approximately half of patients with PHP type 1a and appears to be related to the Gsa deficiency rather than to chronic hypocalcemia, because patients with other forms of PHP and hypocalcemia have normal mentation.

Our patient had features of hypothyroidism, hypocalcemia with high normal PTH along with phenotypic features of Albright's hereditary dystrophy. In addition she had marked anemia secondary to B12 deficiency along with hypokalemia and hypomagnesemia possibly secondary to a renal tubular loss. These were unusual features which could not be explained by pseudohypoarathyroidism alone. We had planned to do X-rays of the hands and feet to document brachycarpals and bracytarsals as well as possible genetic studies to detect the defect in the GNAS1 gene but unfortunately she never came for follow up after the first OP visit

\section{Funding}

None.

\section{Acknowledgements}

My colleagues in the department of Medicine.

\section{Conflicts of interests}

The authors declare that there are no conflicts of interest.

\section{References}

1. Prendiville S, Burman KD, Wartofsky L, et al. Evaluation and treatment of post-thyroidectomy hypocalcemia. Endocrinologist. 1998;8:34.

2. Fitzpatrick LA, Arnold A. Hypoparathyroidism. 2000;1123-1135.

3. Bastepe M. The GNAS locus and pseudohypoparathyroidism. Adv Exp Med Biol. 2008;626:27-40.

4. Long DN, McGuire S, Levine MA, et al. Body mass index differences in pseudohypoparathyroidism type 1a versus pseudopseudohypoparathyroidism may implicate paternal imprinting of Galpha(s) in the development of human obesity. J Clin Endocrinol Metab. 2007;92(3):1073-1079.

5. Nakamura Y, Matsumoto T, Tamakoshi A, et al. Prevalence of idiopathic hypoparathyroidism and pseudohypoparathyroidism in Japan. $J$ Epidemiol. 2000;10(1):29-33.

6. Sanchez J, Perera E, Jan de Beur S, et al. Madelung-like deformity in pseudohypoparathyroidism type 1b. $J$ Clin Endocrinol Metab. 2011;96(9):E1507-E1511.

7. Balavoine AS, Ladsous M, Velayoudom FL, et al. Hypothyroidism in patients with pseudohypoparathyroidism type Ia: clinical evidence of resistance to TSH and TRH. Eur J Endocrinol. 2008;159(4):431-437.

8. Mantovani G, Bondioni S, Linglart A, et al. Genetic analysis and evaluation of resistance to thyrotropin and growth hormone-releasing hormone in pseudohypoparathyroidism type ib. J Clin Endocrinol Metab. 2008;92(9):3738-3742. 